\title{
Tuberculosis: evaluation of the time between identification of symptoms and beginning of treatment
}

\author{
Tuberculose: avaliação do tempo entre a identificação dos sintomas e o início da terapêutica \\ Tuberculosis: evaluación del tiempo entre la identificación de los síntomas y el inicio de la terapéutica
}

'Fundação Santa Casa de Misericórdia do Pará. Belém, Pará, Brazil. "Universidade do Estado do Pará. Belém, Pará, Brazil. "I'Universidade de São Paulo. Ribeirão Preto, São Paulo, Brazil.

How to cite this article:

Oliveira LF, Nogueira LMV, Rodrigues ILA, Palha PF. Tuberculosis: evaluation of the time between identification of symptoms and beginning of treatment.

Rev Bras Enferm. 2020;73(6):e20180902.

doi: http://dx.doi.org/10.1590/0034-7167-2018-0902

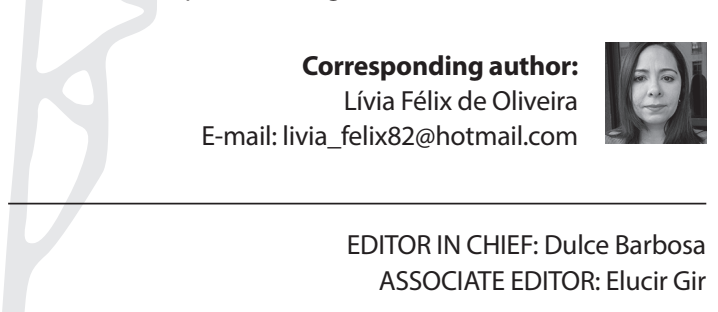

Submission: 02-13-2019

Approval: $02-25-2020$

\begin{abstract}
Objective: To analyze the time elapsed between the identification of respiratory symptoms and the beginning of tuberculosis treatment, considering the sputum smear microscopy and the RMT. Method: Descriptive, retrospective epidemiological study, carried out in two Health Units, which were the only units that performed diagnosis by sputum smear microscopy and Rapid Molecular Test in the city. Data on respiratory symptoms with a positive result for tuberculosis were used. Analysis of data distribution and variance was performed, with a significance level of $5 \%$. Results: The longest time interval found was "result/beginning of treatment", for both tests, with a median of 3 days. It was found that the patient takes longer to receive the result when performing the Rapid Molecular Test. Conclusion: Patients who had the Rapid Molecular Test waited longer for results when compared to sputum smear microscopy, leading to a reflection on the need for further studies on the operation of health services.

Descriptors: Tuberculosis; Delayed Diagnosis; Time; Therapeutics; Molecular Biology.
\end{abstract}

\section{RESUMO}

Objetivo: Analisar o tempo decorrido entre a identificação do sintomático respiratório e o início do tratamento da tuberculose, considerando a baciloscopia e o Teste Rápido Molecular. Método: Estudo epidemiológico descritivo, retrospectivo, realizado em duas Unidades de Saúde, as únicas que realizam diagnóstico por baciloscopia e Teste Rápido Molecular no município. Foram utilizados dados relativos aos sintomáticos respiratórios, com resultado positivo para tuberculose. Realizou-se análise de distribuição dos dados e variância, com nível de significância de 5\%. Resultados: O maior intervalo de tempo encontrado foi "resultado/ início do tratamento", para ambos os exames, com mediana de 3 dias. Foi identificado que o paciente leva mais tempo para receber o resultado quando realiza o Teste Rápido Molecular. Conclusão: O paciente submetido ao Teste Rápido Molecular demorou mais tempo para ter seu resultado liberado quando comparado à baciloscopia, remetendo à reflexão da necessidade de mais estudos sobre a operacionalidade dos serviços de saúde.

Descritores: Tuberculose; Diagnóstico Tardio; Tempo; Terapêutica; Biologia Molecular.

\section{RESUMEN}

Objetivo: Analizar el tiempo transcurrido entre la identificación del sintomático respiratorio y el inicio del tratamiento de la tuberculosis, teniendo en consideración la baciloscopia y la Prueba Molecular Rápida. Método: Se trata de un estudio epidemiológico descriptivo retrospectivo, llevado a cabo en dos Unidades de Salud, las únicas en la ciudad que efectúan diagnóstico por baciloscopia y Prueba Molecular Rápida. Se utilizaron los datos relacionados con los sintomáticos respiratorios que habían dado resultado positivo para la tuberculosis. El análisis de la distribución y de la varianza de los datos apuntó un nivel de significación del 5\%. Resultados: El intervalo más largo fue el de "resultado/inicio del tratamiento", para ambas pruebas, con una mediana de 3 días. Fue posible observar que el paciente tarda más tiempo en recibir el resultado con la Prueba Molecular Rápida. Conclusión: El paciente que se sometió a la Prueba Molecular Rápida tardó más tiempo en saber el resultado en comparación con el de la baciloscopia, lo que demuestra la necesidad de realizar más estudios sobre la operatividad de los servicios de salud.

Descriptores: Tuberculosis; Diagnóstico Tardío; Tiempo; Terapéutica; Biología Molecular. 


\section{INTRODUCTION}

Tuberculosis is a significant cause of death from infectious diseases around the world. In 2017, the incidence rate in Brazil was 33.5/100 thousand inhabitants. The North region was the most affected, with 42.7/100 thousand inhabitants, followed by the Southeast region, with 37.7/100 thousand inhabitants. Among the Brazilian capitals with the highest incidence, Belem occupies the fifth place, with $64.9 / 100$ thousand inhabitants, and, in relation to the mortality rate, it is in second place, with 5.3/100 thousand inhabitants ${ }^{(1)}$.

The National Plan for the End of Tuberculosis as a Public Health Problem in Brazil, created by the Ministry of Health, establishes the first measure for achieving the goals, which is related to prevention and comprehensive patient-centered care, and one of its objectives is diagnosis, with universal access to culture tests, sensitivity tests and rapid tests ${ }^{(1)}$.

The Brazilian Ministry of Health initiated an experimental implementation of the rapid test, also known as Rapid Molecular Test (RMT), GeneXpert or Xpert MTB/RIF, in the primary care of the Unified Health System (SUS), based on reports of expert technicians called by the World Health Organization (WHO), which identified $90 \%$ sensitivity and $99 \%$ specificity ${ }^{(2)}$.

In this context, the RMT was implemented in the city of Belem, so it was necessary to evaluate the efficacy of this new technology. The strategy was to substitute smear microscopy in the diagnosis.

A long period of time between the results of the smear test and the beginning of treatment increases the likelihood of transmission of pulmonary tuberculosis and may make the therapeutic approach more difficult. This is considered a serious problem, since, from the very moment when the health service becomes aware of a positive result, it is their responsibility to begin treatment immediately and to adopt the control measures recommended for breaking the chain of transmission.

Difficulties in the identification of new cases of tuberculosis are more related to the organization of health services than to the methods of diagnosis ${ }^{(3)}$. Thus, it is imperative to pay attention not only to the effectiveness of a new technology, but also to aspects that may point out weaknesses and strengths of the use of this technology. Comparative studies of diagnostic methods may contribute to a reflection on the priorities and need of organization of health services.

The hypotheses proposed in this study were: $\mathrm{H}_{0}$ : the type of test for the diagnosis of tuberculosis influences the time intervals; and $\mathrm{H}_{1}$ : the type of test for the diagnosis of tuberculosis does not influence the time intervals. The objective of the study was to analyze the time elapsed between the identification of respiratory symptoms and the beginning of tuberculosis treatment, considering the sputum smear microscopy and the RMT.

\section{METHOD}

\section{Ethical Aspects}

The research complied with Resolution $466 / 12$ of the National Health Council and was authorized by the Research Ethics Committee of the University of the State of Pará, with Certificate of Presentation for Ethical Consideration (CAAE).

\section{Design, Setting and Period}

This is a descriptive, retrospective epidemiological study, conducted in two Municipal Health Units that perform laboratory processing, including the two diagnostic methods, smear microscopy and RMT, in the city of Belem, state of Pará. Primary Cara Health Units are called here as Health Unit A and Health Unit B. The RMT was implemented in the state of Para in 2015; in Belem, it was implemented exclusively in these two Health Units.

In the city of Belem, the actions for the diagnosis and treatment of tuberculosis are developed in the primary health care network, which has outpatient and hospital back-ups for secondary and tertiary care, respectively. The Health Units selected for the study are part of the primary care network, work with outpatient spontaneous demand and are located in two populous peripheral neighborhoods.

Data were collected from January 2014 to December 2015. In 2014, both health units used sputum smear microscopy as a diagnostic method and, in 2015, these units started to use the RMT for the diagnosis of tuberculosis. Therefore, data from January to December 2014 refer to smear microscopy, whereas in the period from January to December 2015 the data refer to the RMT.

\section{Population}

The data considered in this study was from patients who were over 18 years old, of both genders and diagnosed with pulmonary tuberculosis through sputum smear microscopy or RMT. A total of 261 cases of tuberculosis were included in the study, of which 108 were from Health Unit A and 153 from Health Unit B.

\section{Inclusion and Exclusion Criteria}

The following inclusion criteria were adopted: data regarding respiratory symptoms with a request for a smear microscopy to be performed at the Health Units studied and data regarding respiratory symptoms with a request for an RMT to be performed at the Health Units studied. The exclusion criteria were: data regarding respiratory symptoms that did not collect material for examination in the Health Units under study and data regarding respiratory symptoms that did not perform sputum smear microscopy or RMT.

\section{Study Protocol}

Data were collected from the following sources: book of Records of Respiratory Symptoms, book of Patient Records and Monitoring of Treatment of Tuberculosis Cases, book of Records of Sputum smear and Culture for the Diagnosis and Control of Tuberculosis, patient records, book of records of received sputum samples, and the Notifiable Diseases Information System (SINAN) and Laboratory Environment Manager System (GAL).

The variables studied were age, gender, date of identification of Respiratory Symptoms, date of the test request, date of the collection of the first sample, date of the result of the first sample result, result of the first sample, date of the collection of the second sample, date of the result of the second sample, result of the 
second sample and date of the beginning of the treatment. For the RMT test, the variables were the same, with the addition of the dates of collection and results of the second sample.

\section{Analysis of Results and Statistics}

The time elapsed was calculated in working days, considering the calendar of the Health Units, since results of tests are only available on the days the health service is open. The data were recorded in spreadsheets in Microsoft Office Excel 2016 and transferred to the Statistical Package for Social Sciences (SPSS) version 20.

In the statistical analysis, the Kolmogorov-Smirnov test with the Lilliefors correction was used to identify the type of data distribution. Then, the Levene's test was applied to test the differences between the means after the normality test failed, allowing to ascertain the homogeneity of the variances for each time interval. Subsequently, the F-Test was used to compare the mean variances between two groups.

Since the data was non-parametric, analysis of variance was performed using the Kruskal Wallis test for comparing between the tests, with the objective of identifying the influence of time for each test in each time interval. For statistical validation of the data, a significance level of $5 \%$ was adopted.

As the present research has as starting point the identification of respiratory symptoms and as an end point the beginning of tuberculosis treatment, and considering the findings in the scientific community, it was agreed that this study represents the time of service, which comprehends the time between the identification of respiratory symptoms, which is the first contact with the health service, and the beginning of tuberculosis treatment.

\section{RESULTS}

Table 1 presents the description of the variables in the different time intervals between the identification of respiratory symptoms and the beginning of specific treatment for tuberculosis. As recommended by the Ministry of Health, the diagnosis by smear microscopy requires two collections, while the RMT requires one collection, or two collections when resistance to rifampicin is identified, which explains the $\mathrm{N}^{*}=5$ in the interval $2^{\text {nd }}$ collection $/ 2^{\text {nd }}$ result for the RMT.
The longest time interval was result/beginning of treatment, for both smear microscopy and RMT, with a median of 3 days. The interval $1^{\text {st }}$ collection $/ 1^{\text {st }}$ result had the lowest number of days in both smear microscopy and RMT, with respectively $\mu=0.01$ and $\mu=0.53$ days, not exceeding 1 day. The variance for this time interval was also the smallest, as the result for smear microscopy was 0.01 days and for RMT it was 0.9 days (Table 1 ). For this same interval, the median time was 0 days for both diagnostic tests.

For the interval $2^{\text {nd }}$ collection $/ 2^{\text {nd }}$ result, the mean time of the RMT was higher $(\mu=1)$ when compared to the mean time for the sputum smear microscopy, which was only $\mu=0.05$ days. The interval result/beginning of treatment presented a slightly higher mean for the sputum smear microscopy $(\mu=4.91)$ when compared to the RMT ( $\mu=4.72$ ), both of approximately 5 days (Table 1 ).

Figure 1 shows that, in the interval $1^{\text {st }}$ collection $/ 1^{\text {st }}$ result, the mean variance was lower for the MRT test when compared to the sputum smear microscopy. On the other hand, the mean time elapsed between the 1 st collection and the result is higher for the MRT when compared to the sputum smear, with an average of days exceeding the maximum limit of the mean variance interval (0.4020), while the sputum smear microscopy exceeds the minimum limit of variance (0.2348).

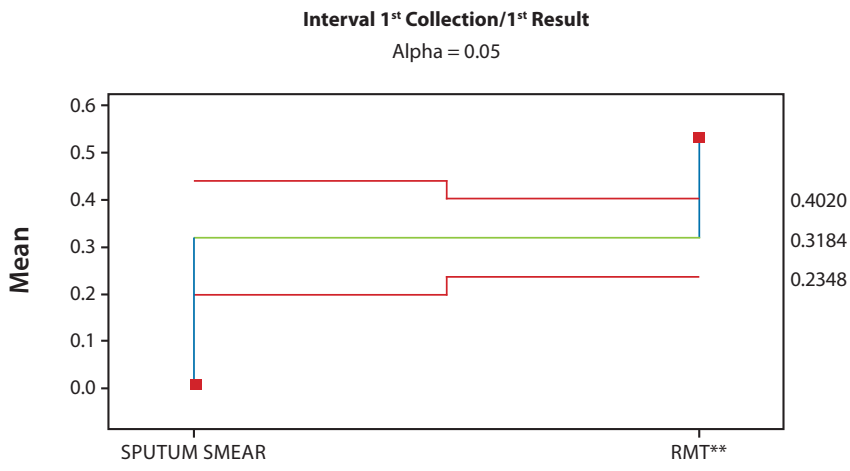

Note: **RMT-rapid molecular test

Figure 1 - Analysis of Variance for the Interval $1^{\text {st }}$ Collection $/ 1^{\text {st }}$ Result between the tests Sputum Smear Microscopy and Rapid Molecular Test

According to Figure 2, the interval $2^{\text {nd }}$ collection $/ 2^{\text {nd }}$ result presented a higher mean variance in the RMT compared to the sputum smear microscopy. Regarding the average time, it was observed that the results of the MRT took longer, with a mean of

Table 1 - Time intervals between the identification of respiratory symptoms and the beginning of treatment, according to the type of test, Belem, Pará, Brazil, 2014-2015

\begin{tabular}{|c|c|c|c|c|c|c|c|}
\hline Variable & Test type & $n^{*}$ & $\mathbf{n}^{\dagger}$ & Mean & SD $^{\ddagger}$ & Variance & Median \\
\hline \multirow{2}{*}{ Interval (Identification of "RS/Test request) } & Sputum smear & 51 & 56 & 0.25 & 1.36 & 1.87 & 0 \\
\hline & $\mathrm{RMT}^{* *}$ & 41 & 113 & 0.56 & 2.51 & 6.30 & 0 \\
\hline \multirow{2}{*}{ Interval (Test request/ $1^{\text {st }}$ Collection) } & Sputum smear & 67 & 40 & 1.01 & 5.62 & 31.59 & 0 \\
\hline & $\mathrm{RMT}^{* *}$ & 104 & 50 & 0.88 & 1.45 & 2.11 & 1 \\
\hline \multirow{2}{*}{ Interval ( $1^{\text {st }}$ Collection $/ 1^{\text {st }}$ Result) } & Sputum smear & 100 & 7 & 0.01 & 0.10 & 0.01 & 0 \\
\hline & $\mathrm{RMT}^{* *}$ & 145 & 9 & 0.53 & 0.90 & 0.82 & 0 \\
\hline \multirow{2}{*}{ Interval ( $1^{\text {st }}$ Result $/ 2^{\text {nd }}$ Collection) } & Sputum smear & 98 & 9 & 1.38 & 1.78 & 3.18 & 1 \\
\hline & $\mathrm{RMT}^{* *}$ & 4 & 150 & 1.50 & 1.73 & 3.00 & 1.5 \\
\hline \multirow{2}{*}{ Interval ( $2^{\text {nd }}$ Collection $/ 2^{\text {nd }}$ Result) } & Sputum smear & 100 & 7 & 0.05 & 0.33 & 0.10 & 0 \\
\hline & $\mathrm{RMT}^{* *}$ & 5 & 149 & 1.00 & 1.00 & 1.00 & 1 \\
\hline \multirow{2}{*}{ Interval (Result/ Beginning of treatment) } & Sputum smear & 81 & 26 & 4.91 & 6.95 & 48.43 & 3 \\
\hline & & 98 & 56 & 4.72 & 7.92 & 62.82 & 3 \\
\hline
\end{tabular}

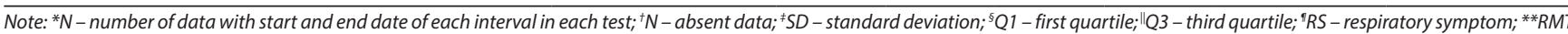
-rapid molecular test. 
approximately 1 day. The results of the sputum smear microscopy took a mean of approximately 0 days.

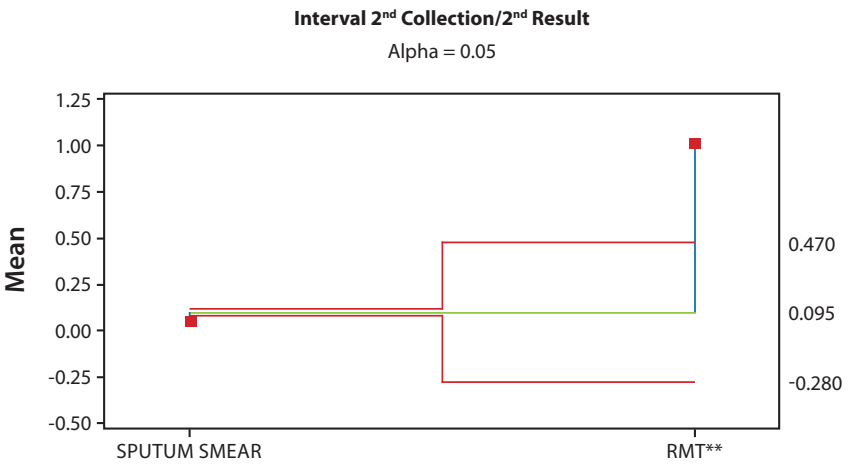

Note: **RMT - Rapid Molecular Test

Figure 2 - Analysis of Variance for the Interval $2^{\text {nd }}$ Collection $/ 2^{\text {nd }}$ Result between the Sputum Smear Microscopy and the Rapid Molecular Test, Belem, Pará, Brazil, 2016

\section{DISCUSSION}

Considering the steps analyzed in this study, beginning with the identification of respiratory symptoms and ending with the beginning of anti-tuberculosis drug therapy, it was necessary to analyze each step of the process.

A systematic review and meta-analysis conducted in 2015 listed the classifications of time intervals of the entire process, from the beginning of symptoms to the beginning of treatment. The authors stated that, in the studies evaluated by them, there were different definitions of delay, mainly in relation to delays in the health institution. Therefore, the lack of standardization in the process limits comparability and proper evaluation ${ }^{(4)}$. Therefore, there is no consensus on an acceptable time for the diagnosis of tuberculosis ${ }^{(5)}$

The shortest period of time identified in this study corresponds to the interval $1^{\text {st }}$ collection $/ 1^{\text {st }}$ result, which had a mean of less than 1 day for both sputum smear microscopy and RMT. Studies with similar designs conducted in Brazil (state of Rio Grande do Sul) and in Durban, South Africa, have identified that the laboratory processing time of the sputum smear had a median of 2.5 days $^{(6)}$, an interval of 0.3 days for sputum smear microscopy and 1.6 days for the rapid molecular test Xpert MTB/RIF(7), the same technology used for the RMT.

Based on these findings, it was observed that, even though the interval $7^{\text {st }}$ collection $/ 1^{\text {st }}$ result presents the shortest period time compared to the other intervals, there is a similarity regarding time in days and the RMT is identified as the most time-consuming diagnostic method when compared sputum smear microscopy, both under the same conditions of laboratory processing and reaching the statistical significance adopted for the studies. In the same logic, the interval $2^{\text {nd }}$ collection $/ 2^{\text {nd }}$ result presented a longer mean time for RMT ( 1 day), when compared to sputum smear microscopy (0.05 day).

Other studies ${ }^{(5,8-9)}$ that addressed this same interval did not detail the two stages of the test, and calculated a "delayed diagnosis" based on the total period of time between the consultation with test request and the final result confirming the diagnosis of tuberculosis. Therefore, it is necessary to foster further research to stratify the time intervals in more detail, allowing a better comparison between studies.

A longer time was identified in the interval "result/beginning of treatment", with a median time of 3 days for sputum smear microscopy and RMT. Some studies have worked on the analysis of this interval and found means and medians of 1 day, 2.5 and 3 days $^{(6,8-10)}$. A comparative analysis between sputum smear microscopy and RMT in Zambia, Africa found that the mean time of the interval between the first consultation and the beginning of treatment was 3 days when the patient was submitted to sputum smear microscopy. Regarding the RMT, the mean time in days, for the same interval and under the same conditions, was 2 days ${ }^{(11)}$. In this case, in addition to the initiative to compare the mean time of the two diagnostic methods, the study found results similar to the present one. This shows the need for a deeper and more critical look at the tuberculosis diagnosis process in the light of new technologies.

The analysis of each time interval in this study showed that the data found here is similar to that identified in national and international literature. However, for comparison purposes, there is a lack of studies that evaluate exactly the same time intervals, and few studies that analyze time intervals with initial and final moments equivalent to those of the present study.

On the same note, a systematic review study ${ }^{(9)}$, defined "heterogeneity in definitions" as a specific topic to be discussed. The authors emphasize the variety of definitions for the types of delay and the heterogeneity in concepts, such as the definition of what is the first contact with the health service or the definition of which symptom is considered as the onset of symptoms, among other observations. Therefore, it is important to be cautious when analyzing the intervals of each study, in order to reduce the risks of confusing the concepts.

The effectiveness of the RMT was recognized by the Brazilian Ministry of Health, who considers that the test offers an opportunity to solve historical problems of tuberculosis, shortening the time for diagnosis. The inclusion of improved molecular tests in the routine of health services can significantly reduce the time for diagnosis and identification of multidrug-resistant tuberculo$\mathrm{sis}^{(12)}$. When analyzing the use of sputum smear microscopy and RMT in the Health Units studied, it was observed that, similarly to what occurs in some countries such as African countries, the RMT equipment is centralized. In other words, only few health services have the equipment, meaning that logistics factors, such as the flow of collection, transportation, processing and issuing of results, may interfere with the impact of the use of technology.

In this perspective, a study about the centralization of the RMT carried out in Africa showed that the availability of the method in a centralized laboratory impairs its use, since this flow causes operational delays twice as long when compared to smear microscopy. These authors mention that these delays limit the clinical utility of $\mathrm{RMT}^{(7)}$. A randomized study that analyzed the impact of the tuberculosis molecular diagnosis system, comparing the method when the machine is available at the health service itself and when the equipment is centralized to serve other services, already demonstrated concern with the impact of the implementation of technology in the flow of the service ${ }^{(13)}$. Therefore, 
it is understood that fewer steps or obstacles can lead to more timely diagnosis and treatment will.

Thus, a centralized laboratory processing generates additional steps that would not be necessary if processing occurred in the same health unit. In the present study, the analysis of the variables was carried out with patients seen at the health unit that owns the RMT equipment. However, the analysis of time is of paramount importance for the diagnosis in patients who are treated in health units adjacent to the units that have the RMT equipment, as it allows analyzing the issue of the relationship between extra steps and time.

There are important differences in the RMT when compared to smear microscopy. However, a critical analysis based on the results of the present study and of others already mentioned shows that some aspects should be highlighted. Based on the definition that the issuing of results of the sputum smear microscopy occurs at most in 24 hours, while the RMT issues results in exactly 2 hours, it is important to analyze these periods of time in the routine of health services.

In the services studied, test results are printed and given directly to the patients, who deliver them to the health team for their next service. There were other punctual situations when the professional requests the result directly in the laboratory of the Health Unit in order to expedite care follow-up. In this sense, it is necessary to establish flows to standardize and optimize care.

The analysis of all the steps of the laboratory processing of the sputum smear microscopy showed that it is totally possible to achieve the target of time for this test. In addition, confirmation of the influence of the type of examination on the time of diagnosis should prompt further studies, due to the finding related to the longer time to issue results of the RMT, when compared to sputum smear microscopy. $A$ priori, this fact should not be attributed to characteristics of the test and its processing, and it can be better studied in the light of the organizational structure and routine of health services.

\section{Limitations of the study}

A limitation of the present study is that it was performed with the data available in the service, which did not always have complete records. In addition, the study was carried out at different times, considering the analysis of the two diagnostic methods and was restricted to the two Health Units in which the RMT was implemented.

\section{Contributions to Nursing, Health or Public Policies}

The results can support public policies for tuberculosis control related to diagnostic tests and allow a reflection on the need to diagnose cases immediately after the identification of the respiratory symptoms. It contributes to nursing practice as nurses have been the professionals of the health team that, throughout the times, have remained as protagonists in control actions within the scope of primary care.

\section{CONCLUSION}

The analysis of time in the tuberculosis control process is of paramount importance for the effectiveness of breaking the transmission chain of $M$. tuberculosis. Unlike the expectation of the Brazilian Ministry of Health that it would speed up the diagnosis of tuberculosis, the RMT proved to be more time consuming, even though it is a test with a processing time of two hours.

Considering that the time difference between the two diagnostic methods occurred in the interval corresponding to the laboratory processing of the test, this finding leads us to reflect on the need for further studies on the organization and operation dynamics of health services.

Technological advances in the health area are at a fast pace; however, their incorporation must be considered only from the perspective of cost-benefit. This is considered the main evaluation criterion; however, the operational aspect, related to the dynamics of the primary care services of the SUS, should be considered in the decision-making process of managers at all levels of government.

It was possible to identify the time for each interval and to analyze the influence of the type of test on the time of diagnosis. In this case, the study showed that the time of each interval was similar and sometimes even shorter than that shown in the national and international literature, considering the design of each study. In addition, it was found that, in the two time intervals in which the test is processed in the laboratory, the RMT presented a longer processing time when compared to sputum smear microscopy, both under the same conditions, following the same protocol of identification of respiratory symptoms, test request, sputum collection, location of sputum delivery, location of test processing and issue of results. The association of factors that may interfere with the time of diagnosis and treatment of tuberculosis was also considered in this study, given the frequency of this approach in almost all studies on the subject. It is assumed that social, economic and cultural factors, habits, religiosity, among others, are determinant in the patient care process and affect the delay or optimization of time. In this setting, the health professional, especially the nurse, becomes a transformative and determining agent in the process of immediate diagnosis and effective treatment of tuberculosis. Considering the presence of these professionals in almost all stages of the process, their effective work, according to the recommendations in the norms and protocols of care, can reduce the delay in diagnosis and treatment. Therefore, this is a scenario that points to the challenge of implementing technologies, with a greater possibility of reaching all aspects that involve the diagnosis and treatment of tuberculosis for its effective control.

\section{REFERENCES}

1. Ministério da Saúde (BR). Secretaria de Vigilância em Saúde. Implantação do Plano Nacional pelo Fim da Tuberculose como Problema de Saúde Pública no Brasil: primeiros passos rumo ao alcance das metas. Bol Epidemiol[Internet]. Brasília: Ministério da Saúde; 2018 [cited 2018 Aug 10];49(11):1-18. Available from: http://portalarquivos2.saude.gov.br/images/pdf/2018/marco/26/2018-009.pdf 
2. Ministério da Saúde (BR). Secretaria de Vigilância em Saúde. Detectar, tratar e curar: desafios e estratégias brasileiras frente à tuberculose. Bol Epidemiol [Internet]. Brasília: Ministério da Saúde; 2015 [cited 2016 Apr 22];46(9):1-19. Available from: http://portalarquivos.saude.gov. br/images/pdf/2015/marco/27/2015-007---BE-Tuberculose---para-substitui----o-no-site.pdf

3. Villa TCS, Ponce MAZ, Wysocki AD, Andrade RLP, Arakawa T, Scatolin BE, et al. Early diagnosis of tuberculosis in the health services in different regions of Brazil1. Rev Latino-Am Enfermagem[Internet]. 2013 [cited 2016 May 15];21(spe):190-8. Available from: http://www. scielo.br/pdf/rlae/v21nspe/24.pdf

4. Cai J, Wang X, Ma A, Wang Q, Han X, Li Y. Factors associated with patient and provider delays for tuberculosis diagnosis and treatment in Asia: a systematic review and metaanalysis. PLoS One[Internet]. 2015[cited 2016 May 15];10(3):e0120088. Available from: https://www.ncbi. nlm.nih.gov/pmc/articles/PMC4373856/pdf/pone.0120088.pdf

5. Machado ACFT, Steffen RE, Oxlade O, Menzies D, Kritski A, Trajman A. Factors associated with delayed diagnosis of pulmonary tuberculosis in the state of Rio de Janeiro, Brazil. J Bras Pneumol[Internet]. 2011 [cited 2016 May 15];37(4):512-20. Available from: http://www.scielo.br/ pdf/jbpneu/v37n4/en_v37n4a14.pdf

6. Sidegum DSV, Gonzales RIC, Harter J, Scherer LC, Pilecco FB. Evaluation of laboratory care provided to patients with respiratory symptoms of tuberculosis seeking public health services in Canoas, Rio Grande do Sul, Brazil, 2012.Epidemiol. Serv Saúde [Internet]. 2015 [cited 2016 May 15];24(4):695-700. Available from: http://www.scielo.br/pdf/ress/v24n4/2237-9622-ress-24-04-00695.pdf

7. Cohen GM, Drain PK, Noubary F, Cloete C, Bassett IV. Diagnostic delays and clinical decision making with centralized Xpert MTB/RIF testing in Durban, South Africa. J Acquir Immune Defic Syndr[Internet]. 2014 [cited 2016 May 15];67(3):e88-e93. Available from: https://www.ncbi. nlm.nih.gov/pmc/articles/PMC4197409/pdf/nihms-618892.pdf

8. Asefa A, Teshome W. Total delay in treatment among smear positive pulmonary tuberculosis patients in five primary health centers, southern Ethiopia: a cross sectional study. PLoS One[Internet]. 2014[cited 2016 May 15];9(7):e102884. Available from: https://www.ncbi.nlm. nih.gov/pmc/articles/PMC4105549/pdf/pone.0102884.pdf

9. Sreeramareddy CT, Qin ZZ, Satyanarayana S, Subbaraman R, Pai M. Delays in diagnosis and treatment of pulmonary tuberculosis in India: a systematic review. Int J Tuberc Lung Dis [Internet]. 2014[cited 2016 May 15];18(3):255-66. Available from: https://www.ncbi.nlm.nih.gov/ pmc/articles/PMC4070850/pdf/nihms-596494.pdf

10. Zhou C, Chu J, Geng H, Wang X, Xu L. Pulmonary tuberculosis among migrants in Shandong, China: factors associated with treatment delay. BMJ Open [Internet]. 2014 [cited 2016 May 15];4(12):e005805. Available from: https://www.ncbi.nlm.nih.gov/pmc/articles/PMC4275669/ pdf/bmjopen-2014-005805.pdf

11. Muyoyeta M, Moyo M, Kasese N, Ndhlovu M, Milimo D, Mwanza W, et al. Implementation Research to Inform the Use of Xpert MTB/RIF in Primary Health Care Facilities in High TB and HIV Settings in Resource Constrained Settings. PLoS One [Internet]. 2015 [cited 2016 May 15];10(6):e0126376. Available from: https://www.ncbi.nlm.nih.gov/pmc/articles/PMC4451006/pdf/pone.0126376.pdf

12. Liu Z, Pan A, Wu B, Zhou L, He H, Meng Q, et al. Feasibility of a new model for early detection of patients with multidrug-resistant tuberculosis in a developed setting of eastern China. Trop Med Int Health. 2017 [cited 2016 May 15];22(10):1328-33. Available from: http:// onlinelibrary.wiley.com/doi/10.1111/tmi.12934/pdf

13. Lessells RJ, Cooke GS, McGrath N, Nicol MP, Newell ML, Godfrey-Faussett P. Impact of a novel molecular TB diagnostic system in patients at high risk of TB mortality in rural South Africa (Uchwepheshe): study protocol for a cluster randomised trial. Trials[Internet]. 2013 [cited 2016 May 15];14:170. Available from: https://www.ncbi.nlm.nih.gov/pmc/articles/PMC3686680/pdf/1745-6215-14-170.pdf 